\title{
New Zealand's perfect storm of entrepreneurship and economic development
}

\author{
Howard Frederick $\cdot$ Erik Monsen
}

Accepted: 10 September 2009/Published online: 30 October 2009

(C) The Author(s) 2009. This article is published with open access at Springerlink.com

\begin{abstract}
Applying a grounded-theory approach to analyzing the Global Entrepreneurship Monitor (GEM) data, we attempt to explain why New Zealand exhibits only a moderate level of economic development despite its high level of entrepreneurship. By statistically analyzing why 34 other countries in the 2005 GEM dataset exhibit small deviations from the classical quadratic curvilinear relationship between entrepreneurship and economic development, we develop a better understanding of the entrepreneurial framework conditions underlying New Zealand's large deviation from this trend line. Based on our findings from the GEM data we make policy recommendations that could aid in moving New Zealand (and other countries) closer toward the trend line and thus promote economic development.
\end{abstract}

Keywords Economic development - GEM · Global Entrepreneurship Monitor · Entrepreneurship · Grounded theory

JEL Classifications L26 $\cdot$ L53 $\cdot$ O11 $\cdot$ O56

H. Frederick $(\bowtie)$

Center for Entrepreneurship, Innovation and Community, Deakin University, Melbourne, Australia

e-mail: howard.frederick@deakin.edu.au

E. Monsen

Entrepreneurship, Growth and Public Policy Group,

Max Planck Institute of Economics, Jena, Germany

\section{Introduction}

A perfect storm is when several remotely possible and individually innocuous events occur at the same time, which then feed off each other and lead to a dramatic and possibly disastrous event. In such a situation it is clear that, if any one element is displaced in time or space, the result would be far less powerful, but because just the right (or wrong) things were in the mix and with just the right (or wrong) timing, the situation grows exponentially worse and is in danger of going out of control. This can happen on the high seas, in a weather system, as well as in an economy. In the latter case, this is sometimes termed creative destruction. While this storm of innovation and entrepreneurship may be disastrous for some, it creates new opportunities for growth and rejuvenation for a region and its economy.

In this paper we explore those factors that could potentially drive such a perfect storm of entrepreneurship and have an unexpectedly negative effect on economic development. Our study uses an inductive rather than a deductive approach in theorizing such a relationship. While we do examine previous theoretical explanations, our aim is to generate a grounded process model of entrepreneurship and economic development. Glaser and Strauss (1967,p. 6) defined their approach thusly: "Generating a theory from data means that most hypotheses and concepts not only come from the data, but are systematically worked out in relation to the data during the course of the 
research." A general research question such as "What's going on?" may be most valuable than formulating hypotheses in advance.

Grounded theory in management research is becoming well developed. This approach is evident in Etemad's (2004) inductive attempt to lay the foundation for a theory relating to internationalization in smaller firm. Stiles (2001) built a theoretical model of gate-keeping and confidence to explain the impact of boards on strategy. Shaffer and Hillman (2000) developed a grounded-theory model for internal conflicts in the formulation of businessgovernment strategies by corporations with diversified business units. De Martino et al. (2006) used grounded theory to create a new conceptual framework on how internationalization impacts on social relationships of locally established firms. Rahman (2003) used the grounded approach in developing a model of how Australian businesses selected their international markets. Randall and Jaya (2006) used grounded theory in their examination of Russian managers. This approach is evident in Liao et al. (2005), who used data-mining techniques to ask "What are the association and temporal patterns of the events and activities that occur in the venture creation process?" Schroeder et al. (2000) similarly develop a grounded theory of entrepreneurial process. Schroeder et al. (2008) use the grounded-theory approach to define the theory of Six Sigma. Mello and Flint (2009) review the foundations of grounded theory in logistics research. Pretorius (2008) used grounded theory in his meta-analysis of business failure. What unites these studies is that theory emerges directly and rigorously out of the data and is returned to the data for verification (Glaser 1992).

In this study, we use empirical data (without presuming hypotheses) in an exploratory fashion, testing best-fit models to create a candidate theory that fits the data. Just like any grounded-theory approach, this study uses a collection of techniques to account for complex patterns in the data. We define constructs, locate indicators, and develop propositions about the relationship of entrepreneurship to economic development, using appropriate methods for correlation and regression analysis.

This paper is structured as follows: Firstly, we report a literature review of factors that have been identified as central to the relationship between entrepreneurship and economic development, identifying major constructs related to the current research. The next section delineates our methodology, including the reports of descriptive statistics, association analysis, and univariate analysis. Results are reported in the third section. The paper concludes with a discussion, propositions, and implications of our study, and suggestions for future research. Based on this new knowledge, we then discuss how such a perfect storm might actually be designed for the benefit of New Zealand, as well as for other regions and countries around the globe.

\section{Literature review}

Our research follows in the stages of economic development tradition (Porter et al. 2002; Lloyd-Ellis and Bernhardt 2000) which hypothesizes that the level of entrepreneurial activity varies with the level of economic development. Researchers have gathered evidence to examine the connection between entrepreneurship and economic development (Wennekers and Thurik 1999; Audretsch 2002; Carree and Thurik 1999). "A mountain of empirical evidence" points to the "positive and statistically robust link between entrepreneurship and economic growth" across a broad spectrum of performance measures (Audretsch 2002a, p. 13). Organisation for Economic Co-operation and Development (OECD) findings suggest that start-up rates are positively associated with economic growth among 20 countries (OECD 2001). Wong et al. (2005) show this positive association with "high-growth" entrepreneurship. Audretsch states that, "While traditional theories suggest that entrepreneurship will retard economic growth, these new theories suggest exactly the opposite-that entrepreneurship will stimulate and generate growth" (Audretsch 2002a, p. 10). Exactly how much influence entrepreneurial activity has on economic growth or development is a matter of ongoing debate among economists. In any case, our dependent variable is not growth (change) but rather economic development as a measure through the proxy of per capita gross domestic product (GDP) corrected for purchasing power parity.

What are the factors that influence entrepreneurial activity and economic development? The model developed by GEM (Reynolds et al. 1999, 2000, 2001, 2002, 2003; Acs et al. 2005; Minniti et al. 2006; 
Arenius and Ehrstedt 2008; Levie and Autio 2008; Bosma et al. 2009) shows that total early-stage entrepreneurial activity (TEEA) ${ }^{1}$ is particularly shaped by a distinct set of factors called "entrepreneurial framework conditions" (EFCs). The EFCs serve as the backbone to entrepreneurial activity but there are many noneconomic entrepreneurial framework conditions (such as government policies and programs, education and training, technology, demography, culture, and social institutions) that influence the rate of start-up entrepreneurship. Extensive reference is made to EFCs in the literature. These influences have been integrated into an eclectic framework (Verheul et al. 2002; Wennekers et al. 2002). This framework is necessarily multidisciplinary in nature and distinguishes between various economic and noneconomic domains.

One of the most cited factors is per capita income. Minniti et al. (2006) show a strong quadratic relationship between early-stage entrepreneurial activity and per capita income (a proxy for economic development). Next to per capita income, other economic factors also impact entrepreneurship. Unemployment basically acts as a push factor for self-employment (Evans and Leighton 1990; Audretsch and Thurik 2001), while social security and welfare benefits determine the opportunity costs of the decision of unemployed persons to seek self-employment (Noorderhaven et al. 2003). The literature also shows that income disparity can stimulate entrepreneurship as a push and a pull factor for self-employment (Ilmakunnas et al. 1999). Additionally, specific technological variables (such as internet access, broadband penetration, and availability of computers) may play a role. Romer sees the type of knowledge capital especially embodied in technology as a "production factor," and this has become especially evident in leading economies (Romer 1986, p. 1003).

Demographic factors that may play a role in entrepreneurship include population growth, age distribution, proportion of ethnicities, level of educational attainment, and female labor participation (Verheul et al. 2002; Wennekers et al. 2002). As regards age distribution, while start-ups occur in all

\footnotetext{
${ }^{1}$ GEM now more correctly labels this as early-stage entrepreneurial activity (ESEA) instead of total early-stage entrepreneurial activity (TEEA), as it appears on some of the literature and in this article.
}

relevant age groups, prevalence rates of nascent entrepreneurship are associated with certain age groups. Education is somewhat of an anomaly. Some research shows that start-up entrepreneurs have attained on average a higher educational level than those in a control sample (Delmar and Davidsson 2000). New Zealand research also confirms that education and entrepreneurship are highly correlated (Frederick 2006). However, in a comparative study across 14 OECD countries, a higher level of education tends to correlate with a smaller proportion of self-employment (Uhlaner et al. 2002). Some attention has focused on labor force participation by gender, suggesting for example that the association of female labor participation with early-stage entrepreneurship is lower than that of men because men are more likely to have the intention to start a firm than are women (Delmar and Davidsson 2000).

Relevant institutions affecting total entrepreneurial activity include the educational system, fiscal legislation, and specific government policies focused on new firms. On the demand side, regulatory policies lowering the barriers to entry and increasing competition influence the opportunities to start a business (Henrekson 2000). On the supply side, institutions play a role in stimulating entrepreneurial capabilities and preferences. This includes such institutions as economic development agencies that help strengthen abilities and motivation, large corporations with an interest in intrapreneurship (entrepreneurial activities within a corporation), educational institutions, and the media (Stevenson 1996). Financial resources such as venture capital and start-up support schemes influence the likelihood of business start-ups. Finally, fiscal legislation (tax rates and tax breaks), the social security system (replacement rates and relative entitlements of the selfemployed), labor market regulation, and bankruptcy legislation are all suggested to influence the rewards and risks of the various occupational opportunities.

The impact of taxes on the level of entrepreneurial activity is complex and even paradoxical (Verheul et al. 2002). High tax rates may reduce the motivation to become an entrepreneur, or being an entrepreneur may offer more ways to avoid tax liabilities. For a selection of 12 OECD countries spanning the period 1972-1996, Parker and Robson (2003) find that self-employment is positively and significantly correlated to personal income tax rates, and negatively and significantly related to employers' social 
security contributions and the unemployment benefit replacement rate. The relationship of social security to entrepreneurial activity may be two-sided. Social security may actually have a positive relationship with entrepreneurial activity by creating a safety net in the case of business failure.

The relationship between entrepreneurial activity and economic development is a complex phenomenon, but as Belso-Martínez (2005, p. 147) summarizes the literature, "it seems reasonable to assume [that there exists] an equilibrium level of the entrepreneurship rate." Various studies (Schmitz 1989; De Wit and Van Winden 1991; Gifford 1998; Bosma et al. 2002, 2003) have recognized the existence and role of an equilibrium entrepreneurship rate. Carree et al. (2007) have even shown that it can be more harmful for economic development to be below the trend line than above it. Despite this confirmation, there are many exogenous factors (which we call the entrepreneurial framework conditions) that generate deviations between the entrepreneurship equilibrium rate and the real rate. Some research (Carree et al. 2000; Audretsch et al. 2002a, b; Wennekers et al. 2005; Minniti et al. 2006; Amoros and Cristi 2008; Bosma et al. 2009) has found a U-shaped relationship between a country's rate of entrepreneurial activity and its economic development that implies a different scope for entrepreneurial policy across the stages of development. Any deviation from the entrepreneurship equilibrium rate, this research argues, can potentially have negative implications for economic development (Belso-Martínez 2005).

Policies have been suggested that can put an economy back on track toward the equilibrium rate. These include technology development, increasing the supply of entrepreneurs, increasing demand for goods and services, and so forth. Summarizing these policies, Wennekers et al. (2005) suggest differential approaches: that advanced nations should focus on start-up incentives and research and development (R\&D) transfer to boost entrepreneurial activity, while developing countries should exploit scale economics, foster foreign direct investment (FDI), and promote entrepreneurship education. From these U-shaped curve results, a notion seems to be emerging that there is a natural rate of entrepreneurial activity based upon the given level of economic growth. However, research has also shown that New Zealand may lie in outlier space, significantly deviating from other observations (Frederick 2006).
In summary, there are many entrepreneurial framework conditions that have been suggested which may correlate with overall total entrepreneurial activity. The challenge is to disentangle these factors and explain differential levels of entrepreneurial activity and economic growth between individual countries and country clusters.

\section{Research questions and analytical model}

To understand New Zealand's unique outlier status, we propose three research questions. First, which entrepreneurial framework conditions (EFCs) account for the most variance in predicting total early-stage entrepreneurial activity (TEEA), over and above the variance explained by GDP per capita accounting for purchasing power parity (GDPPC)? Second, are there differences in the relative impact of these EFCs on TEEA between the two clusters of high-income versus middle-income countries? Third, based on the findings, what policy prescriptions would be recommended for New Zealand to either push or pull it towards the equilibrium or natural rate?

Using the estimated betas from this regression for the population of middle- and high-income GEM countries, we compute the theoretical TEEA* for each individual country, that is, where the country should lie on the U-shaped curve (e.g., quadratic function relating TEEA to GDPPC), as if GDPPC accounted for $100 \%$ of the variance. Given that our goal is to make predictions about New Zealand, based on inferential statistical analysis of the other GEM countries, it is statistically necessary to exclude New Zealand from the estimation of the model coefficients. We model the basic relationship between GDPPC and TEEA as:

TEEA $^{*}=B_{0}+B_{1}$ GDPPC $+B_{2}$ GDPPC $^{2}$.

Next, computing the difference ( $\triangle$ TEEA) between actual TEEA and TEEA* for each country, we then regress this value as our dependent variable against the entrepreneurial framework conditions (EFCs):

$$
\begin{aligned}
& \triangle \mathrm{TEEA}=f(\mathrm{EFCs}) \\
& \text { where } \triangle \mathrm{TEEA}=\mathrm{TEEA}-\mathrm{TEEA}^{*} .
\end{aligned}
$$

Based on our prior discussion of the literature, we expect that a subset of EFCs will emerge from the 
data which help (or hinder) entrepreneurial activity in all countries, as well as a subset that help (or hinder) entrepreneurial activity differently in middle- and high-income countries. Given that New Zealand's GDPPC lies between that of the middle- and highincome countries, we will further need to examine which cluster and corresponding recommendations are most appropriate for New Zealand.

Our grounded-theory approach produced the following four key findings:

Finding 1: There is a quadratic association between TEEA and GDPPC.

Finding 2: New Zealand is an outlier with respect to the quadratic trend line between TEEA and GDPPC.

Finding 3: A subset of EFCs significantly correlate with the residual variance ( $\triangle$ TEEA) of a country's position relative to the quadratic relationship of TEEA to GDPPC, depending on a country's relative level of economic development, e.g., middle income versus high income.

Finding 4: A subset of these EFCs is associated with New Zealand's outlier status.

\section{Research methods}

\subsection{Data and measures}

\subsubsection{Countries and dataset}

The Global Entrepreneurship Monitor research program was designed as a comprehensive assessment of the role of entrepreneurship in national economic development (Reynolds et al. 2005). We used the GEM 2005 data set of 106,495 randomly selected adults in 35 countries taken in June-August 2005 (Minniti et al. 2006). We operationalize our variables as follows:

\subsubsection{Rate of entrepreneurship}

We use the GEM variable total early-stage entrepreneurial activity (TEEA). GEM (Reynolds et al. 2005) uses a narrow cross-nationally validated definition of TEEA: an entrepreneur must have conducted specific activities to start a business in the past year, be an owner or $51+\%$ part-owner of the business, and have paid salaries for more than 3 months. This definition coincides with those who consider venture creation the most appropriate focus on entrepreneurial research (Gartner 1990). The year-to-year correlations are all highly significant at the 0.000 level. We distinguish between two types of early-stage entrepreneurs such that:

$$
\begin{aligned}
\text { TEEA }= & \text { nascent entrepreneurs }(<3 \text { months }) \\
& + \text { new entrepreneurs }(3-42 \text { months }) .
\end{aligned}
$$

\subsubsection{Level of economic development}

We use the 2005 gross domestic product per capita adjusted for purchasing power parity (hereafter simply called GDPPC) as a proxy for economic development.

\subsubsection{Middle-income and high-income countries}

We use the cluster groupings of high- and middleincome countries developed by Minniti et al. (2006). ${ }^{2}$ In essence, the dividing line was US $\$ 25,000$, or the perigee of the quadratic in Fig. 1. The middle-income cluster reflects a negative relation between earlystage entrepreneurial activity and GDP per capita, while the relation for the high-income cluster is tentatively positive. (The GEM sample did not

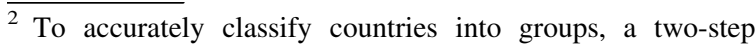
cluster analysis was conducted using the log-likelihood distance measure, to divide the countries that participated in GEM 2005 into groups based on their GDP per capita and their real GDP growth rate in 2005. The first cluster consists of 13 countries from South America, Eastern Europe, and Africa. All of them exhibit relatively high GDP growth rates and middle per capita GDP levels. In fact, the average GDP per capita in this group is only US $\$ 6,252$, whereas their average level of GDP growth is $4.5 \%$. The second cluster contains 22 countries. All of them exhibit high per capita GDP levels, but comparatively lower GDP growth rates. This cluster contains the G7/8 countries and most member states of the European Union, plus Australia and New Zealand. The average GDP per capita for this group is US $\$ 38,722$ and their average growth rate is $2.6 \%$. It is noteworthy that the average values of per capita GDP and GDP growth rates are significantly different among the two clusters at above $99 \%$ confidence, whereas the variation within each cluster is relatively small.
} 
Fig. 1 a TEEA05 by GDPPC05, fitted quadratic curve, and $97 \%$ confidence intervals. b TEEA05 by GDPPC05, fitted cubic curve, and $97 \%$ confidence intervals
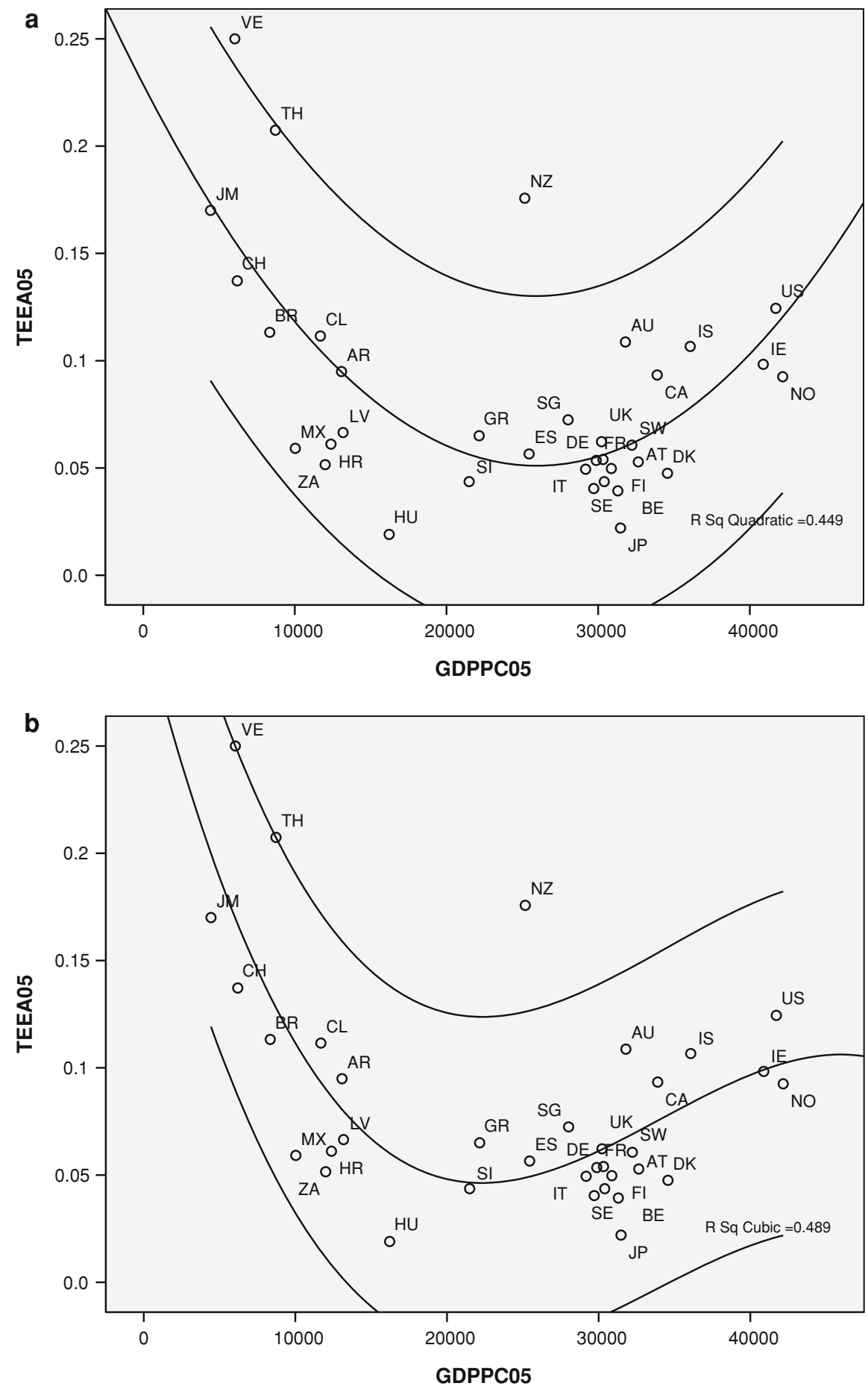

contain any low-income countries <US $\$ 5,000$.) Interesting is the fact that New Zealand just crossed the US \$25,000 boundary in 2005 (International Monetary Fund 2005).

\subsubsection{Entrepreneurial framework conditions (EFCs)}

The GEM dataset includes proxy variables for various economic and social framework conditions 
collected from the World Development Indicators from the World Bank, IMD's World Competitiveness Yearbook, the World Economic Outlook Database, UNESCO Statistics World Education Statistics Time Series Data, EUROSTAT, the Human Development Report, the US Census Bureau, the Population Division of the United Nations, and the Index of Economic Freedom, amongst others. These variables include: measures of national economic development, international trade, government share of the economy, regulatory costs, labor force and employment; human population data, human migration data, educational status data, income disparity and the status of women; as well as computers and internet presence, research science and development.

\subsubsection{Measures of expert opinion}

As well, we include variables of subjective measures of expert opinion in our analysis. Experts in each country selected on the basis of reputation and experience completed a standardized questionnaire to obtain quantitative measures of their opinions concerning deeper measures of the entrepreneurial framework conditions, such as whether intellectual property rights were being respect or whether government was using highly selective criteria in choosing funding recipients, compared with other countries. The various multi-item indices are highly reliable as measured by Cronbach's alpha despite the complex nature of the topic, the multinational administration, and the complexities of ensuring cross-national harmonization.

\subsection{Analytical methods}

In this study we apply a four-step analysis: first, to identify the relationship between entrepreneurial activity and economic development; second, to identify which entrepreneurial framework conditions (EFCs) substantially explain the residual variance between the modeled TEEA and the actual TEEA; thirdly, to identify if there are substantial differences in the impact of these parameters between middleand high-income countries; and fourthly, to confirm if New Zealand exhibits corresponding EFCs that relate to above-average levels of TEEA.

In the first step, we regress TEEA on GDPPC, testing various functional relationships. We consider three specifications: a linear relation and a quadratic specification (U-shape), as indicated by the literature. Finally, in the spirit of "What's going on?", we test a cubic $S$-shaped specification because increasing GEM data may indicate that, as countries become super-rich (e.g., the United Arab Emirates), their level of entrepreneurial activity declines again (see Preiss and McCrohan 2006; and Fig. A1 on page 58 and discussion on page 59 of Minniti et al. 2006). We look at the statistical fit of these three specifications (adjusted $R^{2}$ values).

Second, we propose and follow a straightforward data-screening method based on correlation analysis. The correlation coefficients between $\triangle T E E A$ and the available EFCs are computed separately for two country groups in our sample: middle income and high income. Depending on the statistical significance and the sign of the pairs of correlation coefficients, the variables are assigned to one of the nine quadrants in a $3 \times 3$ grid (Fig. 2).

Next, to test whether the difference between the two correlation coefficients is statistically significant, we first need to apply a Fisher's $z^{\prime}$ transformation to the two correlation coefficients to test the value of the population correlation coefficient $\rho$ applied to the sample correlation coefficient $r$. Following Cohen and Cohen (1983, pp. 53-55), the two $z^{\prime}$ scores are computed as follows:

$z^{\prime}=1 / 2[\ln (1+r)-\ln (1-r)]$.

A final $z$-score is then computed with the following formula, which accounts for differences in group sizes:

$z=\frac{z_{1}^{\prime}-z_{2}^{\prime}}{\sqrt{\frac{1}{n_{1}-3}+\frac{1}{n_{2}-3}}}$.

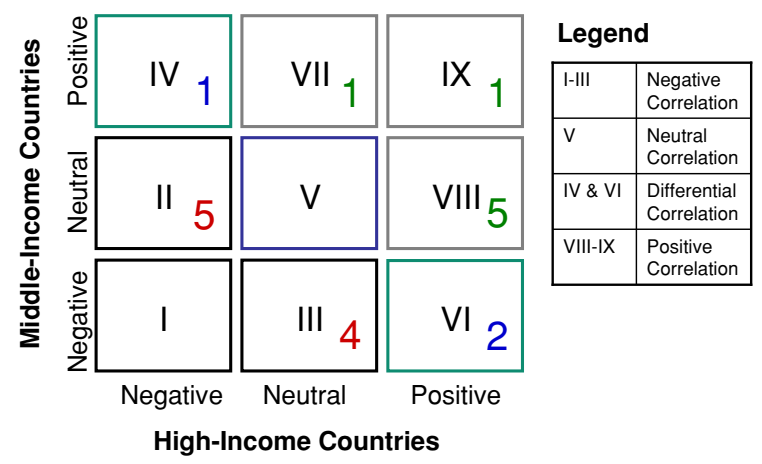

Fig. 2 Map of differential correlation of EFCs with $\triangle$ TEEA 
The significance level of the difference between the two transformed correlation coefficients is then determined. For example, a difference of 1.96 would correspond to the two-tailed $\alpha=0.05$ criterion.

Finally, to determine if this subset of variables contributes to New Zealand's relatively high TEEA level, it is necessary to compute a normalized measure of New Zealand's EFCs, relative to the two populations of middle- and high-income countries. To achieve this, we compute the difference between New Zealand's EFCs and the average EFCs of the two populations, and then divide that difference by the standard deviation of the respective population. With these standardized values, we can compare the relative deviation from the "norm" (equilibrium rate) of the various EFCs and discuss those differences in terms of measure-independent and population-independent standard deviations.

\subsection{Limitations of data and methods}

There are numerous limitations of this study. The adult population sample of GEM countries ranges in error rate due to differing sampling sizes. The comparative national measures used may not serve well as proxies for the entrepreneurial framework conditions mentioned in the literature. There are other entrepreneurial framework conditions mentioned in the literature which we did not test. The sample of countries tested may not be representative, or their numbers $(N)$ may be insufficient. New Zealand has not participated in GEM data collection since 2006. Further research should involve factor analysis and multivariate data analysis with a large sample of countries, but in this present study we are engaged in a hunting expedition in a ground-theory, bottom-up induction process. In addition, time-lag correlations should be computed to test for causality instead of simple correlation. Finally, the data points based on surveys of experts' opinions may differ in quality and statistical performance from the harder economic variables.

\section{Results}

5.1 Finding 1: There is a quadratic association between TEEA and GDPPC

Regarding our first finding, we first confirm previously published findings (Acs et al. 2005; Minniti et al. 2006) that there is a quadratic association between entrepreneurial activity and economic development. We computed correlations between our proxies TEEA/GDPPC and then fitted a trend line. Based on a comparison of $R^{2}$ values, while the linear specification is significant $\left(R^{2}=0.158\right)$, the quadratic U-shaped trend is a much better fit $\left(R^{2}=0.449\right)$. Interestingly, we notice as well that the cubic S-shaped specification $\left(R^{2}=0.489\right)$ replicates the quadratic function, and thus explains slightly additional variance for this constellation of GEM countries. This is graphically represented in Fig. 1a and b, which depict $97 \%$ confidence interval lines above and below the quadratic and cubic fitted trend lines. The $97 \%$ confidence interval lines clearly show how most countries congregate around the fitted line and lie between the upper and lower confidence intervals. Performing the same analysis without the outlier New Zealand results in a quadratic U-shape with a higher fit $\left(R^{2}=0.589\right)$ and an even higher cubic S-shaped specification $\left(R^{2}=0.643\right)$.

Therefore, we have substantial evidence for Finding 1. TEEA appears to decline as countries attain higher GDPPC until GDPPC reaches a turning point at about US $\$ 25,000-27,000$. Then TEEA appears to rise slowly and steadily as per capita GDP rises. One might expect that the curve would ultimately turn down as the rate of entrepreneurial activity in the super-rich countries decreases, but we did not have super-rich countries such as the United Arab Emirates in these data. The countries in the upper left-hand quadrant are all developing countries with high levels of TEEA but low GDPPC. Countries in the US \$10,000-25,000 range tend of have the lowest rates of TEEA. European countries, which have increasingly unified policies, all cluster together. The Anglo-Saxon countries seem to group on the righthand side of the curve.

\subsection{Finding 2: New Zealand is an outlier with respect to the quadratic trend line between TEEA and GDPPC}

Hawkins (1980) captures the concept of an outlier as "an observation that deviates so much from other observations as to arouse suspicion that it was generated by a different mechanism." Perhaps there is something suspicious about New Zealand as it hovers by itself considerably above the trend line. 
The traditional conservative definition of an outlier is an observation that lies two and a half standard deviations from the mean (Barnett and Lewis 1994). With New Zealand at 2.95 standard deviations from the trend line, we have substantial evidence for Finding 2. Further, we find that Venezuela is also an outlier, at 2.69 standard deviations from the trend line. When we exclude New Zealand and Venezuela from our curve fit, the explained variance of the quadratic trend increased from $R^{2}=0.395$ to $R^{2}=0.500$, while with the cubic specification the explained variance increased from $R^{2}=0.395$ to $R^{2}=0.501$, both at less than a 0.001 level of significance, thus providing further evidence for Finding 1 .

However, outliers also have other definitions, since the traditional definition does not scale well to large datasets or marked quadratic relations. Distancebased outlier detection methods are common where the measure of an entity's "outlierness" is based on its distance to nearby entities. The number of nearby observations and the distance between them (specified radius from a data point) are used to identify "data neighborhoods." Knorr and Ng (1998) leave it to the researcher to determine the distance (in feature space) and the fractions or groupings of the rest of the data set. By this measure, we must say that New Zealand's position in outlier space is in a class by itself. New Zealand's high rate of early-stage entrepreneurship (for 5 years running in GEM) is differently associated with economic development from the other countries in the sample.

\subsection{Finding 3: A subset of the EFCs significantly} correlate with the residual variance ( $\triangle$ TEEA) of a country's position relative to the quadratic relationship of TEEA to GDPPC, depending on a country's relative level of economic development, e.g., middle income versus high income

We then ran correlations using $\triangle$ TEEA as the dependent variable against national comparative variables such that $\triangle$ TEEA $=f$ (entrepreneurial framework conditions), according to this model. We calculated Pearson's $r$ and their significances for both our middle-income and high-income country clusters. These could be either positive or negative correlations, or the correlation could be nonsignificant or neutral. In the end, we were especially interested in how the correlations of the EFCs and $\triangle$ TEEA differ for middle- and high-income countries. For example, variables might tend to be negatively associated with middle-income countries and positively associate with high-income countries. To simplify the analysis, we report in Table 1 the nine types of correlations. As diagrammed in Fig. 2, we place each EFC into one of nine categories: EFCs in boxes I-III tended to have a negative correlation; those in box $\mathrm{V}$ had a neutral correlation; those in boxes IV and VI had a differential correlation (positive-negative or negativepositive correlation); and those in boxes VII-IX had a positive correlation. (Variables in box $\mathrm{V}$ are not reported since they have no significant correlation either way.)

Which variables differentiate between middleincome and high-income countries in terms of their position on the TEEA/GDPPC curve? Which variables tend to have positive, negative or differential influences on a country's entrepreneurial activity and economic development? We found 25 variables for which the difference between middle- and highincome countries was significant at a $p$ value of $<0.10$ (see Table 1).

\subsubsection{EFCs with negative relationships}

Nine variables tended to have a negative relationship with a country's position on the TEEA/GDPPC curve. Five (box II) tell a story about the highincome countries and four (box III) about the middleincome countries. Here we are interested in both the correlations with $\triangle$ TEEA and the differences in these correlations. The variables with negative influences were: industry and service sector productivity, level of taxation relative to GDP, gender demographics (\% of males 55-64 years), public health care spending, and three intellectual property variables: (1) respect for inventors' rights, (2) enforcement of intellectual property right legislation, and (3) respect for patents, copyrights, and trademarks. In addition, high selectivity when choosing recipients of entrepreneurial support has a negative correlation in both country clusters.

Some of these findings are to be expected. For example, our findings give credence to the assertion by many, including entrepreneurs themselves, that high tax rates reduce the rate of entrepreneurship and 


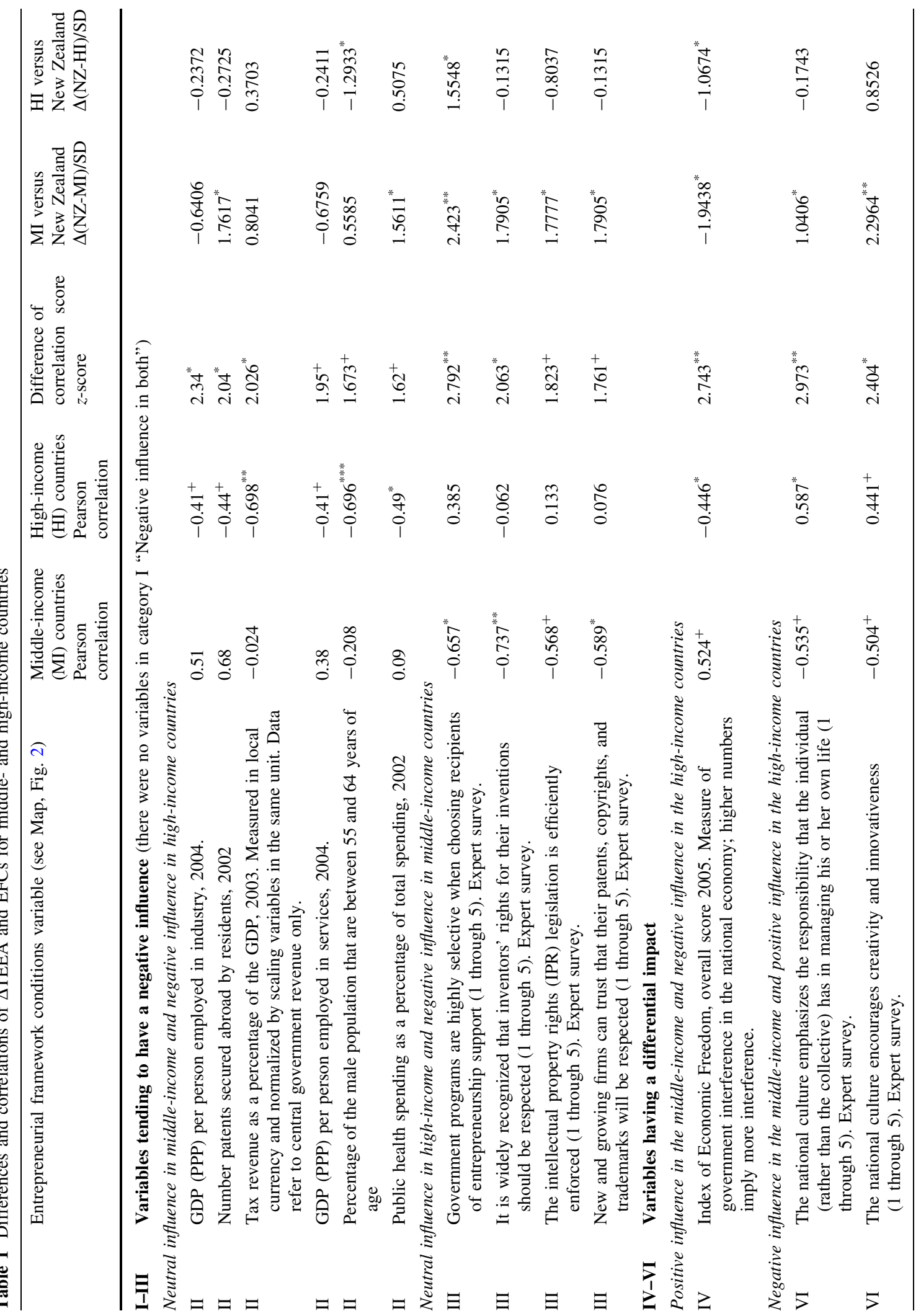




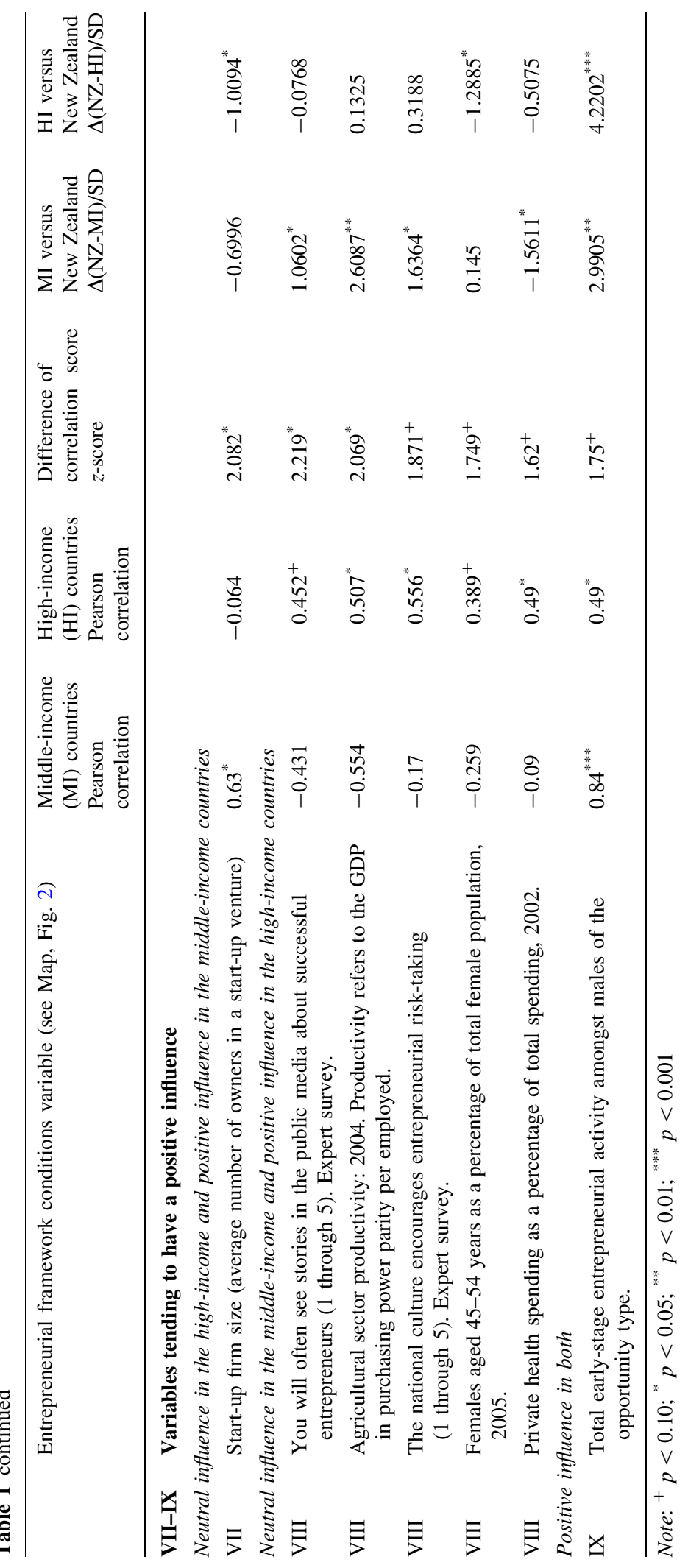


economic development. Similarly, public health spending has a significant negative correlation. This supports the observation, particularly in Nordic countries, that entrepreneurial activity may be inhibited by high levels of welfare spending. In addition, the finding on the prevalence of older males explains why a country such as Japan, which has one of the world's highest "top-heavy" population pyramids, is among the least entrepreneurial of the high-income country cluster.

Some of these findings are curious and unexpectedly interesting. Curious are the findings on the protection of intellectual property rights (IPR). According to our data, IPR protection has a negative relationship with entrepreneurship. These findings suggest that that an unfettered IPR regime characterized by unhampered use of intellectual property actually raises the level of entrepreneurial activity. Another interesting finding is the negative correlation for the use of highly selective criteria in choosing recipients of entrepreneurial grants. This goes against the "pick winners" orthodoxy. It may actually be that highly selective development policy measures are less critical. Just give people funding and assistance and this will lead to entrepreneurial activity and development.

\subsubsection{EFCs with positive relationships}

We now look at the reverse side of the coin. Seven variables tend to have a positive relationship with a country's position on the trend line (box VII-IX): start-up firm size (average number of owners in a new venture), two entrepreneurship cultural variables (media exposure about entrepreneurs and a national culture encouraging entrepreneurial risk-taking), agricultural sector productivity, and two gender demographic variables (\% of females $45-54$ years and the male TEEA opportunity rate).

Nonetheless, there are significant differences between middle- and high-income countries in these variables as well. The most significant difference regards media publicity about successful entrepreneurs, which is more substantially correlated with entrepreneurship in high-income countries. This would encompass entrepreneurs as role models and their position in society. The level of entrepreneurial risk-taking is also more positively correlated with entrepreneurship in high-income countries. This could explain why low risk-taking cultures such as Germany have a lower level of entrepreneurial activity. Alternatively, the number of owners in a new venture also has a positive correlation with entrepreneurship, but much more so for middleincome countries. This suggests that spreading the risk among more owners may have a positive effect on entrepreneurial activity and economic development in middle-income rather than in high-income countries.

One of our most noteworthy findings is the significant difference in the role of agricultural sector productivity in middle- and high-income countries. Our findings suggest that agricultural productivity might be negatively associated with entrepreneurial activity and economic development in middleincome countries but positively associated in highincome countries. A positive correlation between agricultural productivity and entrepreneurship in high-income countries has not been, to our knowledge, previously reported in the literature. It may be that, where farmers are contributing value-added products, especially in high-income countries, this contributes to entrepreneurship and the economy. This would be particularly true in a commoditydriven, pastoral economy such as New Zealand. ${ }^{3}$

The demographic variables also paint an interesting picture from both the male and female perspectives. On the one hand, while the male opportunity entrepreneurship rate is positively correlated with both middle- and high-income country position relative to the $\mathrm{U}$-shaped trend line, this is significantly more positive for middle-income countries. On the other hand, our data suggest that the number of 45- to 54-year-old females is more positively correlated with a country's position relative to the trend line in high-income countries. It is unclear whether this means women as supporters (co-preneurs) of

\footnotetext{
${ }_{3}$ A contrary argument could be made based on the growthregimes perspective of Audretsch and Fritsch (2002), which proposes that some countries perform better with a greater or lesser number of entrepreneurs, based on country-specific economic circumstances. If indeed farming is a comparative advantage for New Zealand, then this may be a specific growth regime for this country, involving many entrepreneurs (farmers). Nonetheless, these authors do show that one of their growth regimes, namely "downsizing regions" (those losing jobs and growth), had a high employment share in agriculture. Closer examination of this point requires more detailed data and more future research.
} 
their male opportunity entrepreneurs or start-up venturers themselves. In either case-whether as co-preneurs or as entrepreneurs-middle-aged women appear to be related to higher levels of entrepreneurship. The question that remains is: why do males appear to play a more positive role in middle-income countries and women a more positive role in high-income countries?

\subsubsection{EFCs with differential relationships}

Finally, we identified three variables where the correlation with entrepreneurship is significant but has the opposite sign in middle- and high-income countries (significantly positive for one country cluster and significantly negative for the other country cluster-boxes IV and VI). These three variables tell even more distinct and exciting stories about the middle- and high-income country clusters.

First, the Index of Economic Freedom has a significant positive correlation for middle-income countries and a significant negative correlation for high-income countries. The Index of Economic Freedom measures the degree of government "interference" in a national economy. In the middleincome countries, increasing government intervention has a positive correlation with entrepreneurship, while it is just the reverse in the high-income countries. This suggests that government "pumppriming" through intervention in business and innovation policies may assist in entrepreneurial take-off in middle-income countries, but once a higher level of economic development has been achieved, government intervention may lead to lower levels of entrepreneurship.

Second, a fascinating finding appears for cultural beliefs regarding individualistic versus collectivistic responsibility. While a culture of individual responsibility may correlate with above-average levels of entrepreneurship in high-income countries, the relationship is reversed in middle-income countries, where a culture of collectivistic responsibility is related to higher levels of entrepreneurship. In other words, the rugged, self-maximizing individualistic entrepreneur, so prevalent as an "ideal type" in the Western research literature and popular press, is only half the picture. In middle-income and less developed countries, collective entrepreneurship, where individual wealth creation is subsumed to the benefit of the group, may in fact have more positive impact on entrepreneurship and economic development.

Similarly, a culture of creativity and innovativeness has a positive relationship with entrepreneurship in high-income countries and a negative relationship in middle-income countries. This might be the case because entrepreneurs in middle-income countries need not be the most innovative; rather, they are more successful if they exploit existing equilibrium opportunities and optimize supply and demand in established markets. Innovativeness and creativity, however, have a positive relationship to entrepreneurship in high-income countries where entrepreneurs should exploit innovative venture opportunities and create new markets. Taking this thought one step further, future research may show that Kirznerian entrepreneurship may be more successful in middleincome countries and Schumpeterian entrepreneurship may be more successful in high-income countries.

\subsection{Finding 4: A subset of these EFCs is associated with New Zealand's outlier status}

Finally, we seek to use the data to explain the differences between the outlier New Zealand and the two country clusters. Here we calculate the significance of the difference between New Zealand's reported EFCs and on the one hand the EFCs of the middle-income countries and on the other hand the EFCs of the high-income countries. Beginning with the set of EFCs identified as being significant in explaining why a country's TEEA would diverge from the trend line (lie above or below the U-shaped curve), we first identify the subset of those parameters where New Zealand is significantly different from both middle-income and high-income countries. The following New Zealand factors are significantly different from both clusters.

\subsubsection{Selectivity}

New Zealand differs from both country clusters on the high selectivity of entrepreneurs for support of initiatives measure. Among the 35 countries in the sample, New Zealand has the highest value of selectivity for entrepreneurial support measures. As New Zealand lies right in the middle of the income 
spectrum (it crossed from middle to high income in 2005), depending on whether we view New Zealand as a middle- or high-income country, this would correspond to lower or higher reported TEEA rates, respectively.

\subsubsection{Economic freedom}

New Zealand has a significantly greater degree of economic freedom than both country clusters. Depending on whether we view New Zealand as a middle- or high-income country, this would correspond to lower or higher reported TEEA rates, respectively.

\subsubsection{Male opportunity entrepreneurship}

New Zealand has a significantly greater degree of male opportunity entrepreneurship than both country clusters. Indeed, New Zealand has some of the highest male opportunity entrepreneurship rates ever recorded in GEM. Again, in both middle- and higherincome countries, this would support the higher TEEA rates reported in New Zealand.

Then we look at factors that significantly separate New Zealand from the high-income countries only. These would include:

\subsubsection{Demographics}

Currently New Zealand has substantially fewer males who are 55-64 years old and substantially fewer females who are 45-54 years old. While fewer older males correlates with a higher TEEA rate, fewer middle-aged females correlates with a lower TEEA rate. In should be noted that the New Zealand median age will be 45 years by 2045 , comparable to Germany (51 years).

\subsubsection{Ownership}

While firms in New Zealand have significantly fewer owners than in high-income countries, this factor does not correlate to more or less TEEA in those countries. It should be noted, however, that we saw that firms with larger numbers of owners have a positive correlation with entrepreneurship rates above the trend line in middle-income countries.
Finally, we examine factors that significantly separate New Zealand from the middle-income countries only. These would include:

\subsubsection{Health spending}

Compared with middle-income countries, New Zealand has significantly more public health spending and significantly less private health spending. It should be noted that, in high-income countries, public healthcare spending is associated with decreased TEEA and private healthcare spending with increased TEEA.

\subsubsection{Intellectual property right protection}

Higher levels of intellectual property protection (respect for inventors' rights; efficient enforcement of intellectual property rights legislation; and respect for patents, copyrights, and trademarks) are associated with lower levels of TEEA in middle-income countries. This would suggest that New Zealand's above-average scores in this area should correspond to lower levels of TEEA, and not the observed higher levels.

\subsubsection{Cultural factors}

GEM data show that New Zealand is above average in terms of business risk-taking when compared with middle-income countries. In particular, the data suggest that the national culture in New Zealand emphasizes individual over collective responsibility in managing one's own life, encourages creativity and innovativeness, encourages entrepreneurial risktaking, and promotes successful entrepreneurs in the media. While these above-average ratings would correspond to lower TEEA in middle-income countries, they contrarily correlate with higher TEEA in higher-income countries.

\subsubsection{Agricultural sector productivity}

New Zealand farmers have high rates of productivity, which we see in the data when compared with middle-income countries. While these above-average ratings would correspond to lower TEEA in middleincome countries, they contrarily correlate with higher TEEA in higher-income countries. 
In summary, while there are a number of factors which strongly support Finding 4, there are several others which provide only mixed support for this finding and require future follow-on research.

\section{Discussion and conclusions}

In this paper we have confirmed that there is a quadratic association between entrepreneurial activity and economic development. We have confirmed that New Zealand is in a class by itself as an outlier to this trend. This finding-New Zealand as outlier-has recently been replicated using a different measure by Bosma et al. (2009, pp. 38-40). We have further confirmed that a subset of the EFCs significantly accounts for the residual variance of countries in our sample relative to the quadratic curve of TEEA to GDPPC, and that this depends on a country's relative level of economic development, e.g., middle income versus high income. Finally, we have identified a subset of EFCs associated with New Zealand's outlier status.

This paper has a number of implications for New Zealand and the rest of the world. The lessons of what may be holding New Zealand in outlier space (i.e., high TEEA rate without correspondingly high GDPPC) arouse our suspicion that different entrepreneurship-generating mechanisms may be at work compared with in other countries. Thus, policy proscriptions for New Zealand need to be different from those for other countries. From a policy perspective, the goal of New Zealand's government is to return the country to the top half of OECD rankings, from which it fell after severing economic ties with Great Britain in 1974. However, we believe that the case of New Zealand demonstrates that certain unhealthy, nondevelopment-oriented factors may be preventing its high TEEA from translating into high GDPPC. Our counterintuitive recommendation would be to contemplate policies that would temporarily reduce New Zealand's inflated TEEA rate in order to let loose factors that could lead to general economic development. We have identified and placed a topfive list of significant factors into a group we call mollycoddling (overprotective) factors. These would include:

\subsection{Taxes}

In high-income countries, entrepreneurs thrive under a moderate tax regime. However, according to the World Bank, total tax payable in New Zealand is $44.2 \%$ of gross profit. By comparison, the USA weighs in at $21.5 \%$ (World Bank 2005). While the intuitive long-term pro-entrepreneurship policy proscription here would be to lower the corporate tax rate, in New Zealand's case the short-term anticoddling policy would actually be to raise tax rates, perhaps in a selective fashion, to generate revenues that could be directed to growth-oriented ventures.

\subsection{Health spending}

Entrepreneurs thrive in a low-welfare-state environment. Averaging about $84 \%$, the Scandinavian countries have the highest public health spending as a proportion of total health spending and some of the lowest TEEA rates in the world. New Zealand comes in second at $78 \%$ (Statistics New Zealand 2006). By this measure, while our long-term intuitive recommendation would be to lower the health security blanket (as well as other welfare measures that ease the pain of unemployment), in the short term in New Zealand's case we would recommend maintaining or even increasing public health care spending, perhaps until the economy picks up and growth-oriented entrepreneurs can cover health-care costs privately.

\subsection{Economic freedom}

New Zealander entrepreneurs might contribute more to economic development if New Zealand was, once again counterintuitively, more interventionist and helped guide entrepreneurial activities in the direction of economic development instead of toward lifestyle ventures that promote independence and satisfaction at the cost of development and wealth creation.

\subsection{Agricultural sector productivity}

New Zealander farmers for decades have had worldrank rates of productivity (without subsidies) and that performance contributes to holding New Zealand in outlier space. Again counterintuitively, our findings suggest that agricultural sector productivity should be 
allowed to decline along with efforts to increase manufacturing and service productivity.

\subsection{Funding selectivity}

The New Zealand rate of selectivity in choosing grant recipients is the highest in the world, according to our data. We believe this selective pampering of some to the detriment of many may be mistaken.

The bottom line is that New Zealand's perfect outlier storm may have something to do with what we call mollycoddling policies (where workers are pampered and enterprise is spoiled). This would fly in the face of New Zealand's pre-2009 Labor-driven orthodoxy to suggest raising corporate taxes, not protecting worker health, increasing government intervention, not picking winners, and loosening dependence on agricultural productivity. However, these are the conclusions we reach from the data.

What we are suggesting is that New Zealanders need to embrace a universe that is in part more Hobbesian. The current Kiwi entrepreneurial disequilibrium of high entrepreneurial activity but lower economic development comes from a singular constellation of events that disfavor creative destruction in the Schumpeterian sense. New Zealand clearly wants to move to the right (higher) along the spectrum of increasing GDPPC, possibly even downward at a loss of entrepreneurial activity, to a higher level of economic development closer to countries such as Iceland, Australia, the USA, and Canada, which have lower TEEA but higher GDPPC (Fig. 1a). This may not be possible under current conditions.

For the rest of the world, this study demonstrates three key points. First, high entrepreneurship rates do not always translate into corresponding economic development. Second, policy measures need to be customized to local conditions. Third, measures that overprotect workers, spoil incentives or indulge welfare passivity can stymie economic development even in conditions of high entrepreneurial activity. In short, sometimes you need to sail directly into a wave to avoid being capsized and sunk by it.

Open Access This article is distributed under the terms of the Creative Commons Attribution Noncommercial License which permits any noncommercial use, distribution, and reproduction in any medium, provided the original author(s) and source are credited.

\section{References}

Acs, Z. J., Arenius, P., Hay, M., \& Minniti, M. (2005). Global entrepreneurship monitor: 2004 Executive report. London: Babson College and London Business School. http://www.gemconsortium.org. Accessed 15 Oct 2009.

Amoros, J., \& Cristi, O. (2008). Longitudinal analysis of entrepreneurship and competitiveness dynamics in Latin America. International Entrepreneurship and Management Journal, 4(4), 381-399.

Arenius, P., \& Ehrstedt, S. (2008). Variation in the level of activity across the stages of the entrepreneurial startup process-evidence from thirty-five countries. Estudios de Economia, 35(2), 133-152.

Audretsch, D. (2002). Entrepreneurship: A survey of the literature (prepared for the European Commission Enterprise Directorate General). Paris: Organisation for Economic Co-operation and Development.

Audretsch, D. B., \& Fritsch, M. (2002). Growth regimes over time and space. Regional Studies, 36(2), 113-124.

Audretsch, D., \& Thurik, R. (2001). What is new about the new economy: Sources of growth in the managed and entrepreneurial economies. Industrial and Corporate Change, 10, 267-315.

Audretsch, D., Thurik, R., Verheul, I., \& Wennekers, S. (2002a). Entrepreneurship: Determinants and policy in a European-U.S. comparison (economics of science, technology and innovation. Boston: Kluwer Academic.

Audretsch, D., Thurik, R., Verheul, I., \& Wennekers, A. (2002b). Entrepreneurship: Determinants and policies in the new economy. Boston, MA: Kluwer Academic.

Barnett, V., \& Lewis, T. (1994). Outliers in statistical data (3rd ed.). John Wiley \& Sons.

Belso-Martínez, J. A. (2005). Equilibrium entrepreneurship rate, economic development and growth. Evidence from Spanish regions. Entrepreneurship and Regional Development, 17(2), 145-161.

Bosma, N., Acs, Z. J., Autio, E., Coduras, A., \& Levie, J (2009) Global entrepreneurship monitor: 2008 Executive report. Global Entrepreneurship Research Consortium (GERA). http://www.gemconsortium.org. Accessed 15 Oct 2009.

Bosma, N., De Wit, G., \& Carree, M. (2003) Modelling entrepreneurship. Tinbergen Institute Discussion Paper, TI-2003-014/3, Tinbergen Institute, Rotterdam.

Bosma, N., Wennekers, S., \& De Wit, G. (2002). Modelling the number of businesses in an equilibrium framework. A time series approach applied to the Netherlands. Zoetermeer: EIM Business and Policy Research.

Carree, M., \& Thurik, R. (1999). Industrial structure and economic growth. In D. B. Audretsch \& R. Thurik (Eds.), Innovation, industry evolution, and employment (pp. 86110). Cambridge: Cambridge University Press.

Carree, M., Van Stel, A., Thurik, R., \& Wennekers, S. (2000). Business ownership and economic growth in 23 OECD countries. Tinbergen Institute Discussion Papers TI 20001/3. Rotterdam: Tinbergen Institute.

Carree, M., Van Stel, A., Thurik, R., \& Wennekers, S. (2007). The relationship between economic development and business ownership revisited. Entrepreneurship and Regional Development, 19(3), 281-291. 
Cohen, J., \& Cohen, P. (1983). Applied multiple regression/ correlation analysis for the behavioral sciences (2nd ed.). Hillsdale, NJ: Lawrence Erlbaum.

Delmar, F., \& Davidsson, P. (2000). Where do they come from? Prevalence and characteristics of nascent entrepreneurs. Entrepreneurship and Regional Development, $12,1-23$.

De Martino, R., Reid, D. M., \& Zygliodopoulos, S. C. (2006). Balancing localization and globalization: Exploring the impact of firm internationalization on a regional cluster. Entrepreneurship and Regional Development, 18(1), 124.

De Wit, G., \& Van Winden, F. (1991). An m-sector, n-group behavioural model of self-employment. Small Business Economics, 3, 46-66.

Etemad, H. (2004). International entrepreneurship as a dynamic adaptive system: Towards a grounded theory. Journal of International Entrepreneurship, 2(1-2), 5-59.

Evans, D. S., \& Leighton, L. S. (1990). Small business formation by unemployed workers. Small Business Economics, 2, 319-330.

Frederick, H. (2006). Global entrepreneurship monitor Aotearoa New Zealand 2005. Unitec School of Management and Entrepreneurship Research Report Series, Vol. 5, No. 1. Auckland: Unitec New Zealand. http:// www.gemconsortium.org. Accessed 15 Oct 2009.

Gartner, W. B. (1990). What are we talking about when we talk about entrepreneurship? Journal of Business Venturing, $5(1), 15-28$.

Gifford, S. (1998). Limited entrepreneurial attention and economic development. Small Business Economics, 10, 17-30.

Glaser, B. (1992). Basics of grounded theory analysis. Mill Valley, CA, USA: Sociology.

Glaser, B. G., \& Strauss, A. L. (1967). The discovery of grounded theory-strategies for qualitative research. New York: Aldine.

Hawkins, D. (1980). Identification of outliers. London: Chapman and Hall.

Henrekson, M. (2000). Personal taxation and the scope for entrepreneurial activity. Paper presented at the Jönköping International Workshop on Institutions, Entrepreneurship and Firm Growth, 13-15 Jan.

Ilmakunnas, P., Kanniainen, V., \& Lammi, U. (1999). Entrepreneurship, economic risks, and risk-insurance in the welfare state. Discussion paper No. 453, Department of Economics, University of Helsinki.

International Monetary Fund, World Economic Studies Division. (2005). World economic outlook database. http://www.imf. org/external/pubs/ft/weo/2004/01/data/index.htm. Accessed 15 Oct 2009.

Knorr, E., \& Ng, R. (1998). Algorithms for mining distance based outliers in large databases. In A. Gupta, O. Shmueli, J. Widom (Eds.), VLDB'98: Proceedings of 24th international conference on very large data bases, August 24-27 (pp. 392-403). New York City, NY: Morgan Kaufmann.

Levie, J., \& Autio, E. (2008). A theoretical grounding and test of the GEM model. Small Business Economics, 31(3), 235-263.

Liao, J., Welsch, H., \& Tan, W. L. (2005). Venture gestation paths of nascent entrepreneurs: Exploring the temporal patterns. Journal of High Technology Management Research, 16, 1-22.

Lloyd-Ellis, H., \& Bernhardt, D. (2000). Enterprise, inequality and economic development. Review of Economic Studies, 67, 147-168.

Mello, J., \& Flint, D. (2009). A refined view of grounded theory and its application to logistics research. Journal of Business Logistics, 30(1), 107-125.

Minniti, M., Bygrave, W. D., \& Autio, E. (2006). Global entrepreneurship monitor: 2005 Executive report. London Business School and Babson College. http://www. gemconsortium.org. Accessed 15 Oct 2009.

Noorderhaven, N., Thurik, R., Wennekers, S., \& Van Stel, A. (2003). Self-employment across 15 European countries: The role of dissatisfaction. SCALES-paper N200223, Zoetermeer: EIM.

OECD. (2001). OECD science, technology and industry scoreboard: Towards a knowledge-based economy. Paris: Organisation for Economic Co-operation and Development.

Parker, S. C., \& Robson, M. T. (2003). Explaining international variations in entrepreneurship: Evidence from a panel of OECD countries. Entrepreneurship Research Series, No. 004. Durham, UK: Barclays Centre for Entrepreneurship, Durham Business School.

Porter, M. E., Sachs, J. D., \& McArthur, J. W. (2002). Executive summary: Competitiveness and stages of economic development. In M. E. Porter, J. D. Sachs, P. K. Cornelius, J. W. McArthur, \& K. Schwab (Eds.), The global competitiveness report 2001-2002 (pp. 16-25). New York: Oxford University Press.

Preiss, K., \& McCrohan, D. (2006). A study of entrepreneurship in the United Arab Emirates 2006. Abu Dhabi: Mohammed Bin Rashid Establishment For Young Business Leaders and GEM United Arab Emirates.

Pretorius, M. (2008). Critical variables of business failure: A review and classification framework. South African Journal of Economic and Management Sciences, N.S., 11(4), 408-430.

Rahman, S. H. (2003). Modelling of international market selection process: A qualitative study of successful Australian international businesses. Qualitative Market Research: An International Journal, 6(2), 119-132.

Randall, L. M., \& Jaya, P. S. (2006). Using grounded theory to unravel complex and context-rich business environments: A study of the Russian manager and business environment. Journal of East-West Business, 12(2-3), 7-37.

Reynolds, P. D., Hay, M., \& Camp, S. M. (1999). Global entrepreneurship monitor: 1999 Executive report. Kauffman Center for Entrepreneurial Leadership.

Reynolds, P. D., Hay, M., Bygrave, W. D., Camp, S. M., \& Autio, E. (2000). Global entrepreneurship monitor: 2000 Executive report. Kauffman Center for Entrepreneurial Leadership. http://www.gemconsortium.org. Accessed 15 Oct 2009.

Reynolds, P. D., Camp, S. M., Bygrave, W. D., Autio, E., \& Hay, M. (2001). Global entrepreneurship monitor: 2001 Executive report. Kauffman Center for Entrepreneurial Leadership. http://www.gemconsortium.org. Accessed 15 Oct 2009. 
Reynolds, P. D., Bygrave W. D., Autio E., Cox L. W., \& Hay, M. (2002). Global entrepreneurship monitor: 2002 Executive report. Ewing Marion Kauffman Foundation. http://www.gemconsortium.org. Accessed 15 Oct 2009.

Reynolds, P. D., Bygrave, W. D., \& Autio E. (2003). Global entrepreneurship monitor: 2003 Executive report. Ewing Marion Kauffman Foundation.

Reynolds, P. D., Bosma, N., Autio, E., Hunt, S., De Bono, N., Servais, I., et al. (2005). Global entrepreneurship monitor: Data collection design and implementation, 1998-2003. Small Business Economics, 24, 205-231.

Romer, P. M. (1986). Increasing returns and long-run growth. Journal of Political Economy, 94(5), 1002-1037.

Schmitz, J. (1989). Imitation, entrepreneurship, and long-run growth. Journal of Political Economy, 97, 721-739.

Schroeder, R., Linderman, K., Liedtke, C., \& Choo, A. (2008). Six sigma: Definition and underlying theory. Journal of Operations Management, 26(4), 536-554.

Schroeder, R., Van de Ven, A., Scudder, G., \& Polley, D. (2000). The development of innovation ideas. In A. H. Van de Ven, H. L. Angel, \& M. S. Poole (Eds.), Research on the management of innovation (pp. 107-133). Oxford University Press.

Shaffer, B., \& Hillman, A. (2000). The development of business-government strategies by diversified firms. Strategic Management Journal, 21(2), 175-190.

Statistics New Zealand. (2006). Demographics and health (Analytical Reports > Human Capital Statistics > Part 1 http:// www.stats.govt.nz/analytical-reports/human-capital-statistics/ part-1-demographics-and-health.htm). Accessed 1 Sep 2007.
Stevenson, L. (1996). The implementation of an entrepreneurship development strategy in Canada: The case of the Atlantic region. Paris: Organisation for Economic Cooperation and Development.

Stiles, P. (2001). The impact of the board on strategy: An empirical examination. Journal of Management Studies, 38(5), 627-650.

Uhlaner, L. M., Thurik, A. R., \& Hutjes, J. (2002). Post-materialism and entrepreneurial activity: A macro view. Proceedings, small business and entrepreneurship development conference, 15-16 April. University of Nottingham.

Verheul, I., Wennekers, S., Audretsch, D., \& Thurik, R. (2002). An eclectic theory of entrepreneurship. In D. Audretsch, A. Thurik, I. Verheul, \& S. Wennekers (Eds.), Entrepreneurship: Determinants and policy in a European-US comparison. Boston/Dordrecht: Kluwer Academic.

Wennekers, S., \& Thurik, R. (1999). Linking entrepreneurship and economic growth. Small Business Economics, 13, 27-55.

Wennekers, S., Uhlaner, L., \& Thurik, R. (2002). Entrepreneurship and its conditions: A macro perspective. International Journal of Entrepreneurship Education, 1, 25-64.

Wennekers, S., Van Stel, A., Thurik, R., \& Reynolds, P. (2005). Nascent entrepreneurship and the level of economic development. Small Business Economics, 24, 293-309.

Wong, P. K., Ho, Y. P., \& Autio, E. (2005). Entrepreneurship, innovation and economic growth: Evidence from GEM data. Small Business Economics, 24, 335-350.

World Bank and International Finance Corporation. (2005). Doing business in 2006. (Explore Topics $>$ Paying Taxes http://www.doingbusiness.org/ExploreTopics/Paying Taxes/). Accessed 15 Oct 2009. 